\title{
Factors Influencing the Use of Outcome Measures for Patients with Low Back Pain: A Survey of Nigerian Physiotherapists
}

\section{Christian Arinze Okonkwo ${ }^{1 *}$, Peter Olanrewaju Ibikunle1, Joseph Onuwa Umunnah ${ }^{1}$, Kenneth Umezulike Ani ${ }^{1}$, Gloria Ukamaka Mgbeojedo ${ }^{2}$, Peter Agba Awhen ${ }^{3}$}

\author{
${ }^{1}$ Department of Medical Rehabilitation, Faculty of Health Sciences and Technology, College of Health Sciences, Nnamdi Azikiwe \\ University, Nnewi Campus, Anambra State, Nigeria \\ ${ }^{2}$ Department of Medical Rehabilitation, Faculty of Health Sciences, College of Medicine, University of Nigeria, Enugu Campus, \\ Enugu State, Nigeria \\ ${ }^{3}$ Department of Physiotherapy, Faculty of Allied Medical Sciences, College of Medical Sciences, University of Calabar, Calabar, \\ Cross River State, Nigeria \\ Email: *ach.okonkwo@unizik.edu.ng, po.ibikunle@unizik.edu.ng, jo.umunna@unizik.edu.ng, uk.ani@unizik.edu.ng, \\ ukamaka.mgbeojedo@unn.edu.ng,peterawhen@unical.edu.ng
}

How to cite this paper: Okonkwo, C.A., Ibikunle, P.O., Umunnah, J.O., Ani, K.U., Mgbeojedo, G.U. and Awhen P.A. (2020) Factors Influencing the Use of Outcome Measures for Patients with Low Back Pain: A Survey of Nigerian Physiotherapists. Open Journal of Therapy and Rehabilitation, 8, 83-97.

https://doi.org/10.4236/ojtr.2020.83008

Received: March 28, 2020

Accepted: August 2, 2020

Published: August 5, 2020

Copyright ( 2020 by author(s) and Scientific Research Publishing Inc. This work is licensed under the Creative Commons Attribution International License (CC BY 4.0).

http://creativecommons.org/licenses/by/4.0/ (c) (i) Open Access

\begin{abstract}
Background: Low back pain is one of the important patients' presenting complain that requires expert management from the physiotherapists. Yet no work was available for reference on the use of outcome measures for its evaluation by Nigeria physiotherapists. Objective: This study, therefore, investigated the outcome measures used by Nigerian physiotherapists to evaluate patients with Low Back Pain and the factors that influenced their use. Methods: A survey questionnaire was posted to 306 randomly selected members of the Nigeria Society of Physiotherapy (NSP). Data were analyzed using frequency, percentages, mean, ANOVA, and Pearson's Chi-square. P-value was placed at 0.05 . Results: $52.9 \%$ of the respondents (221) used a pain visual analog scale. Only $36.1 \%$ used LBP-specific clinical outcome measures. The factors that influenced their use were belief, attitude, knowledge, and choice. There was no significant difference between the majority of the factors and the use of clinical outcome measures. The P-values were $0.960,0.648,0.760$ for belief, attitude and knowledge respectively. The only factor that had a significant difference $(\mathrm{P}=0.029)$ with the use of clinical outcome measures was choice. Gender and postgraduate qualification had no significant influence on the use of clinical outcome measures at the P-value of 0.117 and 0.510 respectively. Conclusion: Pain visual analog scale is the outcome measure frequently used by Nigeria Physiotherapists to evaluate patients with Low Back Pain. Belief, attitude, knowledge, and choice are the factors that influ-
\end{abstract}


enced the use. There is a need to incorporate the use of LBP-specific outcome measures by Nigerian physiotherapists while treating patients with LBP.

\section{Keywords}

Outcome Measures, Factors Influencing Their Use, Low Back Pain Patients, Nigeria Physiotherapists

\section{Introduction}

Outcome measures are tools for measuring the outcome of healthcare interventions over time [1]. Important outcome measures for physiotherapists include changes in patients' impairment, activity limitations, participation restriction, and quality of life, as evaluated with patient self-report measures [2]. Outcome measures have been used for more than 20 years to evaluate the effectiveness of treatment techniques [3]. Studies in Canada, England, and the United States of America (USA), Australia, and Scotland however, have indicated that their use by physiotherapists in routine practice is limited [4]. Also, a survey of New Zealand Physical Therapists on the use of outcome measures for patients with low back pain (LBP) revealed that their use in routine practice was supported by a master's degree and increased knowledge [5]. A study on the familiarity, knowledge and use of standardized outcome measures in the management of different conditions by Nigerian Physiotherapists revealed seldom utilization [6]. At the same, there is an increasing pressure on physiotherapists to demonstrate that their practice is evidenced-based and to document the improvements in patient's functional status [7]. In addition to these pressures, there has been a gradual change in health outcome ideology that could leave a footprint on physiotherapy intervention and the choice of outcome measures. The international classification of function, disability, and Health (ICF) is a framework that promotes more holistic models of patient care, with the focus on enabling patients to participate in the society in contrast to the previous focus on pathology and impairment [8]. For Physiotherapists, this approach means a move away from focusing on pain, muscle strength, or movement patterns toward a greater emphasis on the individuals' goals based on activities and participation.

Low Back Pain (LBP) is an increasing problem both in developed and developing countries whose management is an important component of workload for physiotherapists; however, the effectiveness of physiotherapy management is frequently questioned [9]. The Physiotherapy Pain Association (PPA) which is an integral part of the chartered society of physiotherapy (CSP) recommended the use of standardized outcome measures (SOM) for the management of patients with LBP. The PPA did this, through the panel which was set to analyze the psychometric properties of LBP-specific functional limitation outcome measures. The outcome measures analyzed and recommended for use in routine practice by physiotherapists were: Roland and Morris Disability Questionnaire (RDQ), 
Oswestry Disability Index (ODI), Aberdeen Back pain Scale (ABPS) and Quebec Back Pain Disability Scale (QBDS) [9]. There is no empirical information demonstrating the use of the recommended LBP-specific outcome measures by physiotherapists practicing in Nigeria. This study, therefore, investigated the outcome measures used by Nigeria Physiotherapists in the management of patients with low back pain and the factors which influenced their use.

\section{Methods}

\subsection{Respondents}

306 Physiotherapists who had a minimum of two years of work experience were sampled through the record of Nigeria Society of Physiotherapy.

\subsection{Procedure}

Ethical approval was obtained from the institutional review board of the Nnamdi Azikiwe University Teaching Hospital Nnewi before the commencement of the study. A letter of introduction was obtained from the Medical rehabilitation department, Nnamdi Azikiwe University Nnewi. Fifty-one (51) questionnaires with each attached to introduction letter and consent form were posted (with accompanying stamped return postage envelops) to the physiotherapist in each of the 6 geopolitical zones of Nigeria through a focal person in the following hospitals which served as collation centers from where the Questionnaires were distributed to other hospitals offering Physiotherapy services within each geopolitical zone. South-East: University of Nigeria Teaching Hospital, Enugu State. South-South: University of Port Harcourt Teaching Hospital, River State. South-West: University College Hospital, Ibadan. North-Central: National Hospital Abuja. NorthWest: Ahmadu Bello University Teaching Hospital Zaria, Kaduna State. NorthEast: University of Maiduguri Teaching Hospital, Bornu State. The researchers explained the protocols to the respondents; they were made to understand that their participation in the study would be voluntary and that they would be free to withdraw from the study at any moment in time. Respondents who gave informed consent by thumb-printing or signing the consent form were issued the questionnaire. It was a 13-item close-ended questionnaire that was edited from the one used for a similar population in New Zealand. Item 1 asked about respondents Age. Item 2, Sex. Item 3, Educational qualification (Diploma and Bachelors's degrees). Item 4 asked about postgraduate qualifications. Item 5 asked about the work area in physiotherapy. Item 6 asked about the outcome measure used in the treatment of patients with low back pain in both acute and chronic stages. Item 7 asked the level of satisfaction with the outcome measure used. Item 8 asked about organizational encouragement with the use of outcome measures. Item 9 asked about the use of clinical outcome measures in the last 6 months. Item 10 has 23-subitems arranged on a 5-point Likert scale namely; Strongly Disagree, Disagree, Neither Agree or Disagree, Agree, Strongly Agree. Item 11 requested the source of information about outcome measures. Item 12a asked to state if the information about outcome measures was found helpful. Item $12 \mathrm{~b}$ 
requested to know if the information would encourage interest in their use. A score was given to an item for which a rating was made.

\subsection{Data Analysis}

Out of the 51 Questionnaires posted to each of the six geopolitical zones of the country, the number of questionnaires filled, and returned from each zone were: South-East (SE) 51, South-West (SW) 47, South-South (SS) 30, North-Central (NC) 39, North-East (NE) 19, and North-West (NW) 35. These give a total of 221 returned questionnaires, thereby indicating a $72 \%$ response rate. Data were analyzed using descriptive statistics of frequency, percentages, and mean; with inferential statistics of ANOVA and Pearson's Chi-square.

\section{Results}

The socio-demographic distributions of the respondents are presented in Table 1. 221 physiotherapists (133 males, 88 females) responded to the questionnaire. The majority of the respondents (41.2\%) were not more than 34 years of age, had bachelor's degrees (98.2\%), do not possess postgraduate qualification (71.9\%), and work at physiotherapy outpatient clinics (80.1\%).

Similarly, as seen in Table 2 and Table 3. Majority of the respondents (82.8\%) used outcome measures, moderately satisfied with their use (65.6\%), encouraged by their working organization to use clinical outcome measures (58.8\%), sourced about the outcome measures through colleagues (46.6\%), identified pain visual analog scale as the outcome measure being frequently used in the last six month (52.9\%) (see Table 4). SF-36 was identified as the least used outcome measures (1.4\%). A simple bar chart (see Figure 1 below) was designed to illustrate the clinical outcome measures used by the respondents to evaluate patients with LBP.

Factors that influenced their use of outcome measures (see Table 5).

The factors that influenced the use of outcome measures for patients with Low Back Pain amongst Nigerian Physiotherapists were Belief, Attitude, Knowledge, and Choice.

$\mathrm{N}$-number of the respondents that reported using each outcome measure multiplied by the number of statements that suggested; Belief, Attitude, Knowledge, Time, and Choice.

Mean (for: Belief, Attitude, Knowledge, and Time); is the ratio of the sum of all the marked interval scales (i.e. 1 for strongly disagree, 2 for disagree, 3 for neither agree or disagree, 4 for Agree and 5 for Strongly Agree) to N.

Total in the table below is the average of all the mean values under Belief (3.20), Attitude (3.06), Knowledge (3.66), Time (2.94), and Choice (3.27). These become the factors.

A decision was thereafter taken by the researchers, that any factor whose total mean value is less than 3.0 should not be considered as an influencing factor. Base on this decision, the total mean value for time is less than 3.0, and as such is not considered an influencing factor. 
The interpretation of the mean was based on the cut-off point computed by the researchers. The cut-off point was obtained by adding the weighting of the response categories and dividing by the number. For example $5+4+3+2+1=15$, then $15 / 5=3.00$. The researchers took a decision rule that any item having a mean of 3.00 and above should be interpreted as positive while anyone with mean below 3.00 will be taken as negative. If for example, the study is on factors militating against a certain variable, then all items with mean 3.00 and above will be chosen as factors, and others below 3.00 are not considered as factors [10]. A simple bar chart (see Figure 2 below) was designed to demonstrate the factors which influenced the respondents' use of outcome measures while treating patients with LBP.

There was no significant influence of the factors on the use of clinical outcome measures (see Table 6). Similarly, gender and postgraduate qualifications had no significant influence on the use of clinical outcome measures (see Table 7 and Table 8).

Table 1. Respondents profiles.

\begin{tabular}{|c|c|c|c|}
\hline & Variables & Frequency & Valid percentage \\
\hline \multirow[t]{8}{*}{ Age (in years) } & $25-29$ & 36 & 16.3 \\
\hline & $30-34$ & 91 & 41.2 \\
\hline & $35-39$ & 51 & 23.1 \\
\hline & $40-44$ & 27 & 12.2 \\
\hline & $54-49$ & 12 & 5.4 \\
\hline & $50-54$ & 2 & 0.9 \\
\hline & $55-59$ & 2 & 0.9 \\
\hline & Total & 221 & 100 \\
\hline \multirow[t]{3}{*}{ Sex } & Male & 133 & 60.2 \\
\hline & Female & 88 & 39.8 \\
\hline & Total & 221 & 100 \\
\hline \multirow[t]{3}{*}{ Undergraduate training } & Diploma & 4 & 1.8 \\
\hline & Bachelors degree & 217 & 98.2 \\
\hline & Total & 221 & 100 \\
\hline \multirow[t]{4}{*}{ Postgraduate qualification } & M.Sc & 52 & 23.5 \\
\hline & $\mathrm{PhD}$ & 10 & 4.5 \\
\hline & None & 159 & 71.9 \\
\hline & Total & 221 & 100 \\
\hline \multirow[t]{5}{*}{ Work Area } & Physiotherapy in/outpatient clinic & 177 & 80.1 \\
\hline & Private practice & 17 & 7.7 \\
\hline & Rehabilitation facility & 4 & 1.8 \\
\hline & Other(s) (Academics) & 23 & 10.4 \\
\hline & Total & 221 & 100 \\
\hline
\end{tabular}


Table 2. Respondents' reported methods of Recording Treatment outcome; and their levels of satisfaction, organizational encouragement of the use of clinical outcome measures.

\begin{tabular}{lcc}
\hline Variables & Frequency & Valid percentage \\
\hline Respondents ways of recording treatment outcome & 3 & 1.4 \\
Subjective changes in pain level & 16 & 7.2 \\
Pain maps & 2 & 0.9 \\
Patient's individual goal & 11 & 5.0 \\
Observed improvement in function & 5 & 2.3 \\
Range of movement & 1 & 0.5 \\
Muscle strength & 183 & 82.8 \\
Clinical outcome measures & 221 & 100 \\
Total & & \\
\hline Levels of satisfaction with the methods & 62 & 29.4 \\
Completely satisfied & 145 & 65.6 \\
Moderately satisfied & 7 & 3.2 \\
Neither satisfied nor dissatisfied & 3 & 1.4 \\
Moderately dissatisfied & 130 & 0.5 \\
Completely dissatisfied & 90 & 100 \\
Total & 221 & \\
\hline Organizational encouragement of the use of clinical & & 58.8 \\
outcome measure & 100 \\
Yes & 221 & 40.7 \\
No & & \\
Non & & \\
\hline & & \\
\hline
\end{tabular}

Table 3. Reported sources of information about clinical outcome measures by the respondents.

\begin{tabular}{ccc}
\hline Variable & Frequency & Valid percentage \\
\hline Conference & 12 & 5.4 \\
Colleagues & 103 & 46.6 \\
Professional journals & 17 & 7.7 \\
Books & 42 & 19.0 \\
NSP newsletter & 11 & 5.0 \\
NSP website & 1 & 0.5 \\
In-service training & 24 & 10.9 \\
Others (internet) & 10 & 4.5 \\
Non & 1 & 0.5 \\
Total & 221 & 100 \\
\hline
\end{tabular}

NSP-Nigeria Society of Physiotherapy. 
Table 4. Respondents use of clinical outcome measures in the last 6 months.

\begin{tabular}{lcc}
\hline Variables & Frequency & Valid Percentage \\
\hline Back related clinical outcome measures & 12 & \\
A) RMQ & 40 & 5.4 \\
B) ODI & 8 & 18.1 \\
C) QBPDS & 10 & 3.6 \\
D) ALBDS & 4.5 \\
\hline
\end{tabular}

\section{Other clinical outcome measures}

$\begin{array}{lcc}\text { E) Patient specific functional scale } & 9 & 4.1 \\ \text { F) Pain visual Analogue scale } & 117 & 52.9 \\ \text { G) SF-36 } & 3 & 1.4 \\ \text { H) Others } & 1 & 0.5 \\ \text { I) Do not use a clinical outcome measure } & 21 & 9.5 \\ \text { Total } & 221 & 100\end{array}$

RMQ = Rowland-Morris Disability Questionnaire; ODI = Oswestry Low Back Pain Disability Index; QBPDS = Quebec Back Pain Disability Scale; ALBDS = Aberdeen Low Back Disability Scale; SF-36 = Short Form-36 items medical outcome survey Questionnaire.

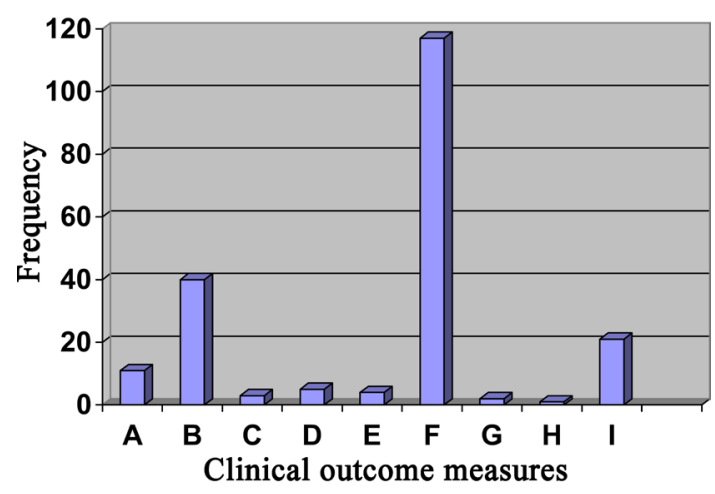

Figure 1. Simple bar chart illustrating respondents' use of clinical outcome measures in the last 6 months.

Table 5. Factor analyses.

\begin{tabular}{ccccccc}
\hline \multirow{2}{*}{ Outcome Measures } & Belief & Attitude & Knowledge & Time & \multicolumn{2}{c}{ Choice } \\
& & A & B & C & C & D \\
\hline \multirow{2}{*}{ RMQ } & Mean & 3.16 & 3.27 & 3.92 & 3.08 & 2.83 \\
& N & 168 & 60 & 12 & 24 & 12 \\
ODI & Mean & 3.26 & 3.19 & 3.82 & 3.08 & 3.03 \\
& $\mathrm{~N}$ & 560 & 200 & 40 & 80 & 40 \\
QBPDS & Mean & 3.17 & 307 & 3.62 & 2.81 & 3.25 \\
& $\mathrm{~N}$ & 112 & 40 & 8 & 16 & 8 \\
ALBDS & Mean & 3.14 & 3.16 & 4.10 & 3.00 & 3.60 \\
& $\mathrm{~N}$ & 140 & 30 & 10 & 20 & 10 \\
Patient-specific & Mean & 3.27 & 3.07 & 3.78 & 2.61 & 3.21 \\
functional scale & $\mathrm{N}$ & 26 & 45 & 9 & 18 & 9 \\
\hline
\end{tabular}




\section{Continued}

\begin{tabular}{ccccccc}
\hline Pain Visual & Mean & 3.19 & 2.97 & 3.56 & 2.88 & 3.33 \\
Analogue Scale & $\mathrm{N}$ & 1638 & 582 & 117 & 234 & 117 \\
& $\mathrm{Mean}$ & 3.12 & 3.27 & 3.00 & 2.67 & 3.33 \\
SF-36 & $\mathrm{N}$ & 42 & 15 & 3 & 6 & 3 \\
& $\mathrm{Nean}$ & 3.42 & 2.80 & 3.00 & 2.50 & 5.00 \\
Others & $\mathrm{N}$ & 14 & 5 & 1 & 2 & 1 \\
& & & & & & \\
Do not use clinical & Mean & 3.16 & 3.12 & 3.62 & 3.00 & 3.95 \\
Outcome measures & $\mathrm{N}$ & 294 & 105 & 21 & 42 & 21 \\
& $\mathrm{Mean}$ & $\mathbf{3 . 2 0}$ & $\mathbf{3 . 0 6}$ & $\mathbf{3 . 6 6}$ & $\mathbf{2 . 9 3}$ & $\mathbf{3 . 2 7}$ \\
Total & $\mathrm{N}$ & $\mathbf{3 0 9 4}$ & $\mathbf{1 1 0 5}$ & $\mathbf{2 1}$ & $\mathbf{4 4 2}$ & $\mathbf{2 2 1}$
\end{tabular}

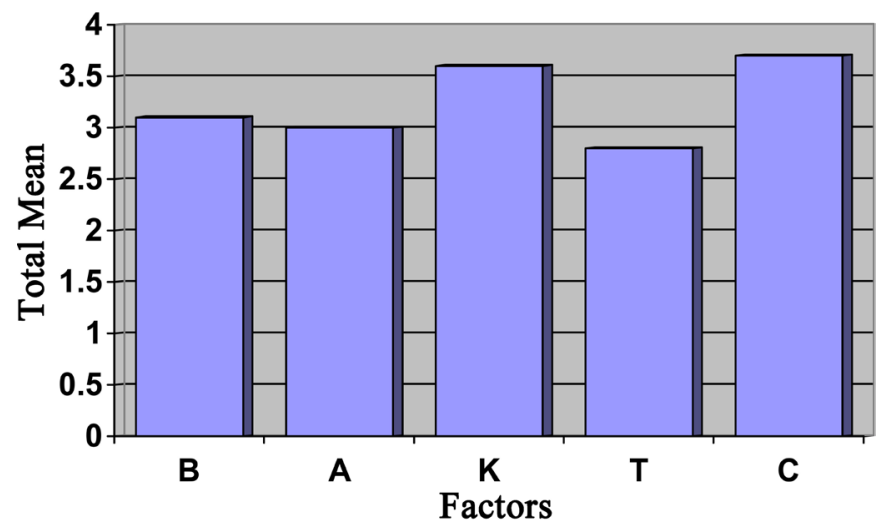

Figure 2. Simple bar chart illustrating the mean of the factors.

Table 6. ANOVA table showing influencing of factors on outcome measures.

\begin{tabular}{|c|c|c|c|c|c|}
\hline Factors outcome measure & Sum of squares & Df & Mean square & $\mathrm{F}$ & Significance \\
\hline \multicolumn{6}{|l|}{ Believe* outcome measures } \\
\hline Between groups (combined) & 5.003 & 8 & 0.625 & \multirow{2}{*}{0.316} & \multirow{2}{*}{0.960} \\
\hline within groups & 6107.725 & 3085 & 1.980 & & \\
\hline Total & 6112.755 & 3093 & & & \\
\hline \multicolumn{6}{|l|}{ Attitude $^{\star}$ outcome measures } \\
\hline Between groups (combined) & 12.068 & 8 & 1.509 & \multirow{2}{*}{0.749} & \multirow{2}{*}{0.648} \\
\hline Within groups & 2206.870 & 1096 & 2.014 & & \\
\hline Total & 2218.864 & 1104 & & & \\
\hline \multicolumn{6}{|l|}{ Knowledge ${ }^{\star}$ outcome measures } \\
\hline Between groups (combined) & 7.001 & 8 & 0.875 & \multirow{2}{*}{0.621} & \multirow{2}{*}{0.760} \\
\hline Within groups & 298.863 & 212 & 1.410 & & \\
\hline Total & 305.864 & 220 & & & \\
\hline \multicolumn{6}{|l|}{ Choice $^{\star}$ outcome measures } \\
\hline Between groups (combined) & 20.273 & 8 & 2.559 & \multirow{2}{*}{2.194} & \multirow{2}{*}{0.029} \\
\hline Within groups & 247.238 & 212 & 1.166 & & \\
\hline Total & 267.710 & 220 & & & \\
\hline
\end{tabular}


Table 7. (a) Outcome measures ${ }^{\star}$ gender cross-tabulation; (b) Chi-Square Tests.

(a)

\begin{tabular}{|c|c|c|c|c|c|}
\hline \multirow{3}{*}{$\begin{array}{l}\text { Outcome } \\
\text { measures }\end{array}$} & \multicolumn{2}{|c|}{ Gender } & \multirow{2}{*}{$\begin{array}{c}\text { Male } \\
8\end{array}$} & \multirow{2}{*}{$\begin{array}{c}\text { Female } \\
4\end{array}$} & \multirow{2}{*}{$\begin{array}{c}\text { Total } \\
12\end{array}$} \\
\hline & \multirow[t]{2}{*}{ RMDQ } & Count & & & \\
\hline & & $\%$ within gender & $6.0 \%$ & $4.5 \%$ & $5.4 \%$ \\
\hline & \multirow[t]{2}{*}{ OLBPDI } & Count & 27 & 13 & 40 \\
\hline & & $\%$ within gender & $20.3 \%$ & $14.8 \%$ & $18.1 \%$ \\
\hline & \multirow[t]{2}{*}{ QBPDS } & Count & 7 & 1 & 8 \\
\hline & & $\%$ within gender & $5.3 \%$ & $1.1 \%$ & $3.6 \%$ \\
\hline & \multirow[t]{2}{*}{ ALBPS } & Count & 9 & 1 & 10 \\
\hline & & $\%$ within gender & $5.3 \%$ & $1.1 \%$ & $4.5 \%$ \\
\hline & \multirow{2}{*}{$\begin{array}{l}\text { Patient-specific } \\
\text { functional scale }\end{array}$} & Count & 4 & 5 & 9 \\
\hline & & $\%$ within gender & $3.0 \%$ & $5.7 \%$ & $4.1 \%$ \\
\hline & \multirow{2}{*}{$\begin{array}{l}\text { Pain Visual Analogue } \\
\text { Scale }\end{array}$} & Count & 67 & 50 & 117 \\
\hline & & $\%$ within gender & $50.4 \%$ & $56.8 \%$ & $52.9 \%$ \\
\hline & \multirow[t]{2}{*}{ SF-36 } & Count & 2 & 1 & 3 \\
\hline & & $\%$ within gender & $1.5 \%$ & $1.1 \%$ & $1.4 \%$ \\
\hline & \multirow[t]{2}{*}{ Others } & Count & 0 & 1 & 1 \\
\hline & & $\%$ within gender & $0.0 \%$ & $1.1 \%$ & $0.5 \%$ \\
\hline & \multirow{2}{*}{$\begin{array}{l}\text { Do not use a clinical } \\
\text { outcome measure }\end{array}$} & Count & 9 & 12 & 21 \\
\hline & & $\%$ within sex & $6.8 \%$ & $13.6 \%$ & $9.5 \%$ \\
\hline \multirow[t]{2}{*}{ Total } & & Count & 133 & 88 & 221 \\
\hline & & $\%$ within sex & $100.0 \%$ & $100.0 \%$ & $100.0 \%$ \\
\hline
\end{tabular}

(b)

\begin{tabular}{cccc}
\hline & Value & Df & Assume Sig (2-sided) \\
\hline Pearson Chi-square & 12.846 & 8 & 0.117 \\
Likelihood Ratio & 14.307 & 8 & 0.074 \\
\hline
\end{tabular}

Table 8. (a) Clinical outcome measure ${ }^{\star}$ Postgraduate Qualification Cross tabulation; (b) Chi-square Tests.

(a)

\begin{tabular}{|c|c|c|c|c|c|c|c|c|c|c|}
\hline & \multicolumn{6}{|c|}{ Clinical outcome measures } & \multirow[b]{2}{*}{ SF-36 } & \multirow[b]{2}{*}{ Others } & \multirow[b]{2}{*}{ None } & \multirow[b]{2}{*}{ Total } \\
\hline & RMQ & ODI & QBPDS & ALBDS & $\begin{array}{l}\text { Patient-specific } \\
\text { functional scale }\end{array}$ & $\begin{array}{l}\text { Pain visual } \\
\text { Analogue }\end{array}$ & & & & \\
\hline \multicolumn{11}{|l|}{ No postgraduate qualification. } \\
\hline Count. & 7 & 33 & 5 & 7 & 7 & 80 & 2 & 1 & 17 & 159 \\
\hline$\%$ with outcome measures. & $58.3 \%$ & $82.5 \%$ & $62.5 \%$ & $70.0 \%$ & $77.8 \%$ & $68.4 \%$ & $66.7 \%$ & 100 & 81.0 & 71.9 \\
\hline \multicolumn{11}{|l|}{ M.Sc } \\
\hline Count & 4 & 7 & 2 & 2 & 2 & 32 & 0 & 5 & 3 & 52 \\
\hline$\%$ within outcome measures & $33.3 \%$ & $17.5 \%$ & $25.0 \%$ & $20.0 \%$ & $22.2 \%$ & $27.4 \%$ & $0.0 \%$ & $0.0 \%$ & $4.3 \%$ & $23.5 \%$ \\
\hline \multicolumn{11}{|l|}{$\mathrm{PhD}$} \\
\hline Count & 1 & 0 & 1 & 1 & 0 & 5 & 1 & 0 & 1 & 10 \\
\hline$\%$ within outcome measures & $8.3 \%$ & $0.0 \%$ & $12.5 \%$ & $10.0 \%$ & $0.0 \%$ & $4.3 \%$ & $33.3 \%$ & $0.0 \%$ & $4.8 \%$ & $4.5 \%$ \\
\hline \multicolumn{11}{|l|}{ Total } \\
\hline Count & 12 & 40 & 8 & 10 & 9 & 117 & 3 & 1 & 21 & 221 \\
\hline$\%$ within outcome measures & $100 \%$ & $100 \%$ & $100 \%$ & $100 \%$ & $100 \%$ & $100 \%$ & $100 \%$ & 100 & $100 \%$ & $100 \%$ \\
\hline
\end{tabular}


(b)

\begin{tabular}{cccc}
\hline & Value & $\mathrm{df}$ & Assume significance (2-sided) \\
\hline Pearson chi-square & $15.201^{\mathrm{a}}$ & 16 & 0.510 \\
Likelihood Ratio & 14.626 & 16 & 0.552 \\
N of Valid cases & 221 & & \\
\hline
\end{tabular}

\section{Discussion}

This study explored the outcome measures used by Nigerian physiotherapists in the management of patients with low back pain and the factors which influenced their use. Pain visual analog scale was revealed as the frequently used outcome measure by the respondents in the treatment of patients with low back pain. This may be because it is easily understood by both the therapist and the patients. The scale only assesses the level of pain intensity, thus may not be suitable for a functional evaluation concerning the specific predictor of pain, implying that the scale is not standardized as opposed to LBP-specific outcome measures. The use of pain visual analog scale as a routine outcome measure for patients with LBP was never established in previous studies however a Canadian study [2] had reported pain rating scale which is similar to pain visual analog scale because it is also a measure of pain intensity. LBP-specific functional outcome measures were rarely utilized with ODI being the frequently used LBP-specific functional outcome measure. This finding may be so, because the respondents may have specialized in areas of physiotherapy not common with periodic review and treatment of low back pain. A similar study carried out in New Zealand [5] and United States of America [11] had a higher percentage report of using LBP-specific functional outcome measures when compared with this study which may have been encouragred by effective health insurance mechanisms where a therapist may be required to provide outcome of treatment in order to secure payment claims. This study however demonstrated a slight improvement in the use of standardized outcome measures when compared with previous Nigerian study [6] which revealed that 14 out of 16 standardized outcome measures were not used. The awareness created by the previous study may have facilited the observed slight improvement found in this study.

The result also revealed that the least used clinical outcome measure for the patients with LBP is SF-36. This could be because SF-36 is not an LBP-specific standardized outcome measurement tool. However, the least frequently used LBP-specific functional outcome measure is QBPDS. This was not established in any of the previous studies. However previous studies consistently reported poor utilization of standardized outcome tools [6].

The factors influencing the use of outcome measures in the treatment of patients with low back pain by Nigerian Physiotherapists were Belief (3.20), Attitude (3.06), Knowledge (3.66), and Choice (3.27). Belief (physiotherapists believe in the values associated with the use of clinical outcome measures), Attitude (physiotherapists approach towards the use of clinical outcome measures), knowledge 
(information about clinical outcome measures by physiotherapists), and choice (disparity associated with choosing one amongst numerous clinical outcome measures). Time (2.93), frequently mentioned in the previous studies did not meet up with the statistical requirement to be called an influencing factor because time is not up to average statistical mean score as considered by the researchers. Also, physiotherapists may have not allotted sufficient time in evaluating the outcome of their intervention concerning low back pain treatment. Knowledge with the highest mean score emerged as the strongest factor. Knowledge was also established as a factor in a previous study [6]. Attitude and Knowledge were also established as factors in a Dutch study [4]. Increased knowledge, belief and choice were also established as a factor that influenced the use of outcome measures in a New Zealand study [5].

There was no significant difference between the factors and the use of clinical outcome measures except for choice which is the only factor that demonstrated a strong significance (P-value was 0.029 as against assumed $\mathrm{P}$-value of 0.05$)$. Belief $(\mathrm{P}$-value $=0.960)$, Attitude $(\mathrm{P}$-value $=0.648)$, knowledge $(\mathrm{P}$-value $=0.760)$ showed no significant difference with the use of clinical outcome measures (see Table 6 above). This finding suggests that Physiotherapists need to adapt a workable approach that will facilitate the use of LBP-specific outcome measures. Increased knowledge and a demonstrable positive attitude towards LBP-specific outcome measures may be helpful. A New Zealand study [5] revealed knowledge as the only factor that is statistically significant with the use of outcome measures. An Australian study [2] revealed that attitude at P-value of 0.02 was fairly significant with the use of outcome measures. Knowledge showed a significant difference $(P<0.05)$ in a previous Nigerian study [6] on the use of standardized outcome measures.

There was no significant influence of gender on the use of clinical outcome measures. The P-value was 0.117 (see Table 7 (b) above). This implies that both genders used clinical outcomes for patients with LBP equally and that no particular gender used the outcome measures more frequently than the other. This has not been established in previous studies. Postgraduate qualification ( $\mathrm{P}$-value $=$ 0.510 ) showed no significant influence with the use of clinical outcome measures (see Table 8(b) above). This implies that a higher degree was not necessarily a determinant for the use of outcome measures. This could be since the postgraduate qualification listed by the respondents may have been studied in other subspecialties rather than back-related or pain-related subspecialty. A New Zealand study [5] revealed that a master's degree had a significant $(\mathrm{P}$-value $=0.05)$ difference with the use of outcome measures.

\section{Conclusion}

Pain Visual Analogue Scale was the outcome measure frequently used by Nigeria Physiotherapists to evaluate patients with LBP. LBP-specific standardized clinical outcome measures were largely underutilized, with ODI being the LBP-specific 
clinical outcome tool accorded a fair utilization. The factors that influence the use of the outcome measures are belief, attitude, knowledge, and choice. There was no significant difference between the clinical outcome measures and the factors. Gender and postgraduate qualifications had no significant influence on the use of clinical outcome measures. There is therefore a need to incorporate the frequent use of LBP-specific outcome measures by Nigerian physiotherapists while treating patients with LBP.

\section{Conflicts of Interest}

The authors declare no conflicts of interest regarding the publication of this paper.

\section{References}

[1] Australian Physiotherapy Association (2003) Position Statement: Clinical Justification Outcome Measures.

[2] Abrams, D., Clancy, J., Davidson, M., Harcourt, P., Harrick, J. and Zylinski, M. (2006) Monitoring the Change: Current Trends in Outcome Measure Usage in Physiotherapy. Journal of Manual Therapy, 11, 46-53. https://doi.org/10.1016/j.math.2005.02.003

[3] Schaufele, M.K. and Boden, S.D. (2003) Outcome Research in Patients with Chronic Low Back Pain. Orthopedic Clinics of North America, 34, 231-237. https://doi.org/10.1016/S0030-5898(03)00030-0

[4] Stevens, J.G.A. and Buerskens, A.J.M.H. (2010) Implementation of Measurement Instruments in Physical Therapist Practice: Development of a Tailored Strategy. Physical Therapy, 90, 953-961. https://doi.org/10.2522/ptj.20090105

[5] Copland, J.M., Dean, S.G. and Taylor, W.J. (2008) Factors Influencing the Use of Outcome Measures for Patients with Low Back Pain: A Survey of New Zealand Physical Therapists. Journal of American Physical Therapy Association, 88, 1492-1505. https://doi.org/10.2522/ptj.20080083

[6] Akinpelu, A.O. and Eluchie, N.C. (2006) Familiarity with Knowledge, and Utilization of Standardized Outcome Measure among Physiotherapists in Nigeria. Journal of Physiotherapy Theory and Practice, 22, 61-72. https://doi.org/10.1080/09593980600564469

[7] Beurskens, A.J., de Vet, H.C. and Koke, A.J. (1996) Responsiveness of Functional status in Low Back Pain: A Comparison of Different Instrument. The Journal of International Association for the Study of Pain, 65, 71-76. https://doi.org/10.1016/0304-3959(95)00149-2

[8] World Health Organization (2006) International Classification of Function Disability and Health. https://www.who.int/classifications/icf/en/

[9] Physiotherapy Pain Association (2004) Recommendations for Low Back Pain — Related Functional Limitation Outcome Measures. https://www.csp.org.uk/

[10] Uzoagulu, A.E. (1998) Practical Guide to Writing Research Project Reports. Jacobs' Publishers Enugu, Nigeria.

[11] Jette, D.U., Halbert, J., Iverson, C., Miceli, E. and Shah, P. (2009) Use of Standardized Outcome Measures in Physical Therapist Practice: Perceptions and Applications. Physical Therapy, 89, 125-135. https://doi.org/10.2522/ptj.20080234 


\section{Questionnaire for Mail Survey}

Adapted from Previous Studies by Copeland, Taylor, and Dean (2008), Wellington School of Medicine.

\section{Questionnaire}

1. How old are you? Please tick one box.

\begin{tabular}{|c|c|c|c|}
\hline $20-24$ & $25-29$ & $30-34$ & $35-39$ \\
\hline $40-44$ & $45-49$ & $50-54$ & $55-59$ \\
\hline
\end{tabular}

\section{Please tick one box}
Male
Female

3. What is your undergraduate training? Please tick one box.

Diploma

Bachelor's Degree

4. Do you have any postgraduate qualifications? Please list these:

5. What is your work area? Please tick one box

1. Physiotherapy outpatient clinic

2. Private practice

3. Rehabilitation facility

4. Gym or fitness center

5. Rest home

6. Other (Practice Elaborate)

6. Low back pain is commonly divided into (lasting less than 3 months) and chronic. Bearing this in mind, please indicate how to record the outcomes of your treatments for patients with acute low back pain and then for patients who present with B) chronic low back pain? Please tick the boxes that apply.
A) Acute
B) Chronic

1. Subjective changes in pain level

2. Pain maps

3. The patient's individual goals

4. The observed improvement in function

5. Range of movement

6. Muscle strength

7. Clinical outcome measures

8. Please add any measures that you routinely use to record the outcome of your treatment:

7. Are you satisfied with the method that uses? Please tick one box

1. Completely satisfied

2. Moderately satisfied

3. Neither satisfied nor dissatisfied 
4. Completely dissatisfied

5. Completely dissatisfied

6. Have you any comments on the methods you use?

8. Clinical outcome measures are a standardized way of measuring patient outcomes. Is the use of clinical outcome measures encouraged in your organization or service are? Tick one box
Yes
No
Comments:

9. Low back pain is commonly divided into acute (lasting less than 3 months) and chronic. If you have used clinical outcome measures. Please indicate which, if any, of the outcome measures below you have used when treating patients with low back pain in the past 6 months.

This list is only some of the possible outcome measures; please add any other measures that you routinely use in the treatment of low back pain to the end of the list.

Outcome Measures
1. Roland-Moris Disability Questionnaire
2. Oswestry Low Back Pain Disability Index
3. Quebec Back Pain Disability Scale
4. Aberdeen Low Back Pain Scale
5. Patient-Specific Functional Scale
6. Pain Visual analog Scale
7. SF-36
8. Please add any measures you use:
9. OR I do not use clinical outcome measures

10. Please rate each of the following statements regarding your treatment of patients with LBP by putting a tick in the appropriate box.

\begin{tabular}{|c|c|c|c|c|}
\hline & $\begin{array}{l}\text { Strongly } \\
\text { Disagree }\end{array}$ & $\begin{array}{c}\text { Neither } \\
\text { Agree } \\
\text { or Disagree }\end{array}$ & Agree & $\begin{array}{c}\text { Strongly } \\
\text { agree }\end{array}$ \\
\hline 1 Health professionals should measure the outcomes of their treatments & & & & \\
\hline 2 Clinical outcome measures enable you to get a better understanding of your patients' progress & & & & \\
\hline 3 My patients are all different, therefore, clinical outcome measures would not be useful & & & & \\
\hline 4 If I had more time, I would be interested in using clinical outcome measures & & & & \\
\hline 5 Functional outcome test and measures are unpopular with clients & & & & \\
\hline 6 Patient satisfaction is the most important outcome & & & & \\
\hline 7 Clinical outcome measures are not suitable for the patient presenting with acute LBP & & & & \\
\hline 8 I do not know enough about clinical outcome measures to feel comfortable using them & & & & \\
\hline
\end{tabular}


9 Ideally, the measurement of functional outcomes should be a priority

10 There is no need to change from the ways that we have always used to assess patients

11 Access to information on clinical outcome measures is limited in my work environment

12 Health professionals should monitor progress using reliable and valid tools

13 I would be interested in learning more about clinical outcome measures

14 It is not necessary to measure functional outcomes

15 The use of validated outcome measures is clinically helpful in an increasing

15 medicolegal environment

16 Available tests are inappropriate for the type of patients I treat

17 I am interested in using clinical outcome measures in my practice

${ }_{18}$ The clinical outcome measures available are not suitable for the ethnic/cultural mix of my patients

19 II do not see the use of clinical outcome measures as a priority

20 The use of clinical outcome measures could help justify ongoing treatment by EBP

21 The patient failing to complete a course of treatment puts me off using clinical outcome measures

22 I do not have enough time to use clinical outcome measures

23 If I had to use clinical outcome measures, I would prefer to choose the ones I used

11. In the past year, have you used any of the following resources to obtain information about outcome measures? Please tick all the relevant boxes.
1. Conferences
2. Colleagues
3. Professional journals
4. Books
5. NSP newsletter
6. NSP web site
7. In-service training
8. Other (please elaborate)

Resource

12a. What information about clinical outcome measures would you find helpful?

\section{$12 \mathrm{~b}$. Would this information encourage your interest in their use?}

Thank you for your time in completing this questionnaire. Please return the completed questionnaire in the stamped addressed envelope.

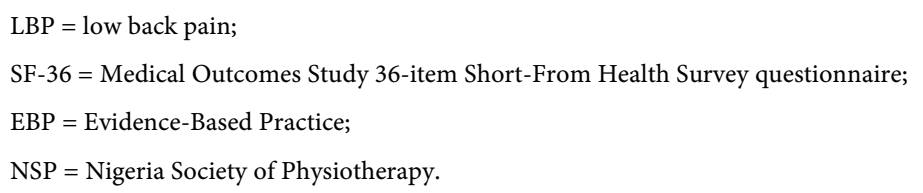

